\title{
Receptivity to 2010 Census Messages Among the General Public and Hard-to- enumerate Populations
}

\author{
W. Douglas Evans ${ }^{1 *}$, Ting Yan ${ }^{2}$ and A. Rupa Datta ${ }^{2}$ \\ ${ }^{1}$ The George Washington University, School of Public Health and Health Services, USA \\ ${ }^{2}$ NORC at the University of Chicago, USA
}

\begin{abstract}
Message receptivity is a construct that represents rational and affective reactions to messages and has been used to predict changes in attitudes toward public service advertising. Health communication studies show that receptivity can act as a mediator of behavior change. This study extends the receptivity construct to prediction of Census participation.

The 2010 Census Integrated Communication Campaign Evaluation measured receptivity to the 2010 Integrated Communication Campaign, an advertising campaign designed to promote Census participation. This study aimed to identify differences in receptivity to Census messages between advertisements and targeted populations and opportunities to improve messages in future.

Measured items loaded onto a single receptivity factor. We regressed Census cognitions and behaviors on the receptivity factor in the general population and examined differences between hard-to-enumerate subpopulations targeted by the campaign. Higher receptivity was associated with more positive cognitions about the 2010 ICC. Higher receptivity was also associated with more positive attitudes and beliefs about the Census. Receptivity was associated with higher Census participation among some hard-to-enumerate populations and is an important construct for future media campaigns.
\end{abstract}

Keywords: Message receptivity; Media campaign; Hard-to-reach populations; Census participation

\section{Introduction}

\section{Message receptivity}

Message receptivity (MR) is a construct that represents rational and affective reactions to messages [1]. A number of studies in health communication have established measures of "receptivity" to public service advertising (PSA) that capture audiences' subjective appraisals of message persuasiveness, believability, and other aspects of cognitive processing $[2,3]$. These measures have been shown to predict changes in attitudes toward the social issues and other subject matter of PSAs [4]. Such measures can be used to assess effectiveness of PSA campaigns and as mediators to test the theory underlying a campaign during and after implementation [5].

Receptivity is based on research on factors influencing message processing through central and peripheral cognitive functions. The Elaboration Likelihood Model (ELM) of cognitive processing [6] posits that rational message appeals are processed through central cognitive functions, whereas emotional appeals are process through peripheral functions. The mode of processing affects how recipients respond to messages. Recent studies in health communication in subject areas ranging from tobacco control to reproductive health have validated multi-dimensional scales of message receptivity based on ELM [1,7].

Two related theories, the Activation Model of Information Exposure (AMIE) [8], and the Limited Capacity Model of Mediated Message Processing (LCM) [9], further propose a variety of stylistic message components that promote audience receptivity to messages. This research has been used in the design of message testing studies and measures of message recall, receptivity and response [1].

Studies based on the LCM have explored the effects of specific visual, audio, and format features on attention and processing $[9,10]$. Other studies examine the effects of specific message features on message recall using population surveys $[10,11]$. Studies based on AMIE examine attention to messages as a function of an individual's need for sensation (NFS, also called sensation seeking) and the level of stimulation provided by the message. Recent studies report correlations between NFS and health risk behaviors such as drug use and risky sex $[12,13]$. These theories provide a foundation for message receptivity as an explanatory construct in health communication [5].

\section{Census campaign and evaluation background}

Message receptivity may be an important factor in evaluating outcomes of other types of PSA campaigns, such as civic participation, but there are few examples [14]. The largest recent case in the US is the Census 2010 Integrated Communication Campaign (2010 ICC), which was designed to maximize Census participation among traditionally hard-to-enumerate (i.e., low response) populations. In the conceptual model of the Census Integrated Communications Program Evaluation (2010 CICPE) [14], message receptivity is conceptualized as a mediator between 2010 ICC exposure and cognitive (i.e., knowledge, attitudes and beliefs about the Census) and behavioral (i.e., participation) outcomes.

Census 2000 was the first decennial census to use a paid advertising campaign. Evidence suggests that the Census 2000 Partnership and

*Corresponding author: W. Douglas Evans, The George Washington University, 2175 K Street, NW, Suite 700, Washington DC, USA, E-mail: wdevans@gwu.edu

Received September 05, 2012; Accepted October 16, 2012; Published October 24, 2012

Citation: Douglas Evans W, Yan T, Datta AR (2012) Receptivity to 2010 Census Messages Among the General Public and Hard-to-enumerate Populations. J Mass Commun Journalism 2:126. doi:10.4172/2165-7912.1000126

Copyright: () 2012 Douglas Evans W, et al. This is an open-access article distributed under the terms of the Creative Commons Attribution License, which permits unrestricted use, distribution, and reproduction in any medium, provided the original author and source are credited. 
Marketing Program, along with other efforts aimed at improving census participation, succeeded in reversing a long-term decline in mail response rates, especially in traditionally hard-to-enumerate groups [15], and improved cooperation with Census Bureau enumerators [15].

In 2010, the Census Bureau used an approach that integrated a mix of mass media advertising, digital and social media, targeted media outreach to specific populations, national and local partnerships, grassroots marketing, school-based programs, and special events. The media mix was 'integrated' in that multiple channels were combined based on audience media use to maximize exposure to the messaging in the general population and in hard-to-enumerate groups [16]. By integrating media, the campaign's goal was to reach everyone in the country. The campaign began in late 2009 and ran through June, 2010.

The purpose of the study is to compare associations between exposure to 2010 ICC advertising executions and knowledge, attitudes, beliefs and intentions to participate in the 2010 Census. This is important to understand differences in marketing and message strategies and potential to improve campaign messages and cognitive and behavioral outcomes in future. Specifically, we examine whether higher levels of message receptivity are associated with greater knowledge about the Census, more positive beliefs about its benefits, intention to participate and ultimately participation. If message receptivity predicts improved cognitive and behavioral outcomes, future messages should be tested for receptivity, differences in receptivity between groups, and the messages that score highest should be used in future campaigns.

The study's primary hypotheses $(\mathrm{H})$ and research questions (RQ) are as follows:

(H1) MR measures used in the 2010 CICPE will load onto a single MR factor.

(H2) Higher MR will be associated with more positive and/or higher levels of cognitions including knowledge attitudes, beliefs, and intentions regarding Census participation.

(H2a) Specifically, higher MR will be associated with more positive Census cognitions among hard-to-enumerate sub-populations?

(RQ1) Is higher MR associated with higher odds of actual Census mail return?

(RQ1a) Specifically, is higher MR associated with greater actual Census mail return among hard-to-enumerate sub-populations?

\section{Methods}

The 2010 CICPE aimed to: 1) track the evolution of knowledge of and attitudes toward the Census prior to and during the 2010 Census; 2) evaluate the effect of the 2010 ICC on mail return and cooperation with enumerators; 3) increase understanding of the mechanisms through which a communications campaign can affect census participation; and 4) emphasize the perspectives of hard-to-enumerate groups in achieving these analytical objectives [16].

The principal data source was a set of three nationally-representative household surveys conducted between October 2009 and July 2010 to capture knowledge, attitudes and exposure to the campaign. To increase the ability to understand person-specific campaign response, the 2010 CICPE included a panel sample in which the same individuals were interviewed in each of the three waves. Survey samples included approximately equal numbers of individuals from five hard-toenumerate groups and one comparison group (Hispanic, non-Hispanic
African American, American Indian, Asian, Native Hawaiian, and non-Hispanic Whites).

Data collection took place at three time points. Wave 1 was conducted mid-September 2009 through mid-January 2010 to assess baseline levels of all measures of public attention and intentions regarding the 2010 ICC. Wave 2 took place January 19 through March 18, 2010, during the peak of the campaign activities, but before households received their Census forms. Finally, Wave 3 was conducted during the period from mid-April through mid-July, 2010 when people had made their decisions about participating in the mail return phase and had been exposed to the full course of the campaign.

Due to the complex design and methodology in the 2010 CICPE, rather than describe those methods in depth here we refer readers to the study's final report, which is available online (http://2010.census. gov/2010census/pdf/). The final report provides in-depth descriptions of the study design, data collection methodology, analyses, detailed data tables, and interpretation of findings.

The Wave 3 CICPE questionnaire was designed to give a picture of the cumulative or total exposure to the paid media campaign, and possible effects on cognitions, since it occurred right after the conclusion of paid advertising and other major outreach efforts. Additionally, the Wave 3 interview captured information about receipt of the Census form and whether respondents completed and returned it.

We used wave 3 data in this analysis. Each respondent was asked whether they remembered seeing or hearing three specific advertisements - an advertisement designed for the general population (called 'diverse mass'), a target population specified advertisement (i.e., one intended for a subpopulation such as Hispanic Americans who primarily speak Spanish), and a nonresponse follow-up (NRFU) ad (i.e., one implemented late in the campaign to encourage individuals who had not already mailed back their Census form to do so). The ads were selected primarily because they received a substantial fraction of air time during the 2010 ICC, but also because testing during questionnaire development indicated that the chosen ads were easier to describe and recognize than other ads in the campaign. For each ad, three receptivity questions were asked:

- Would you say the ad grabbed your attention? (YES, NO)

- Would you say the ad gave you good reason to mail back your Census form? (YES, NO)

- During the past 90 days, how often have you seen this advertisement? (Never, once or twice, 3-15 times, 16 to 30 times, or 31 times or more)

We recoded the first two questions so that 1 equaled YES and 0 represented everything else. For the third question, never was recoded as 0 , once or twice as $1,3-15$ times as 2,16 to 30 times as 3, and 31 times or more as 4 . We also combined data on actual 2010 Census participation derived from Census records to determine households campaign response.

We report two sets of analyses. First, we examined the relationship between self-reported knowledge, attitudes and beliefs, and intent to participate as the dependent variables and MR as the independent variable. Second, we examined the relationship between actual Census mail return as the dependent variable and MR as the independent variable. 


\begin{tabular}{|c|c|c|c|c|c|c|}
\hline Item & Mean & SE & $\begin{array}{l}\text { Factor } \\
\text { Loading }\end{array}$ & $\begin{array}{l}\text { Item-Scale } \\
\text { Correlation }\end{array}$ & $\begin{array}{l}\text { Inter-item } \\
\text { correlation }\end{array}$ & Alpha \\
\hline $\begin{array}{l}\text { This ad was attention } \\
\text { grabbing. }\end{array}$ & 0.12 & 0.01 & 0.94 & 0.90 & 0.85 & 0.82 \\
\hline $\begin{array}{l}\text { Ad gave good reasons } \\
\text { to mail Census form. }\end{array}$ & 0.13 & 0.01 & 0.92 & 0.88 & 0.81 & 0.85 \\
\hline $\begin{array}{l}\text { How often have you } \\
\text { seen this ad? }\end{array}$ & 0.29 & 0.02 & 0.89 & 0.94 & 0.75 & 0.90 \\
\hline \multicolumn{7}{|l|}{$\begin{array}{l}\text { Message Receptivity } \\
\text { Index }\end{array}$} \\
\hline $\begin{array}{l}\text { (summary of the } 3 \\
\text { variables) }\end{array}$ & 0.54 & 0.04 & --- & --- & & \\
\hline
\end{tabular}

Table 1: Descriptive Statistics and Reliability Analysis of Message Receptivity Index.

\section{CICPE Self-report analyses}

Based on the above item re-coding, we scored message receptivity to each ad for each respondent. Using these scores, we conducted exploratory factor analyses on the three MR items at the individual ad level (i.e., MR by ad by respondent). Based on the widely accepted [17] standards, we found that the three MR variables loaded onto one factor (Table 1). In order to estimate campaign effects across the three ads, we then calculated an overall MR index at the respondent level by summing up the MR factor scores across all three ads. The resulting MR index was used in all subsequent models.

Next we fit three models to examine whether or not the MR index predicted respondents' Census knowledge, attitudes and beliefs, and intent to participate. To measure respondents' knowledge of the Census, scores were computed for each respondent by counting the correct answers to the 8 knowledge questions asked in wave 3 . The 8 knowledge measures consisted of a series of Yes-No questions about the benefits and implications of accurate Census information (e.g." "Is the Census used...to decide how much money communities will get from the government?")

The 11 attitudinal measures consisted of 4-point agreement scales about individual's beliefs about the Census and its benefits or consequences (e.g., "The Census Bureau's promise of confidentiality can be trusted."). We conducted an exploratory factor analyses on these items. Two factors were extracted; 10 items loaded onto one factor and one item (about the burden of the Census) loaded onto a second factor. We subsequently used the first factor.

Intent to participate in the Census was measured with a survey question asked in wave 2 about how likely respondents would return their Census form if the Census were held today. The model for intent was only run on panel respondents who completed all three waves.

All models were run in SAS Version 9.1 (Cary, NC) with the PROC SURVEYREG or PROC SURVEYLOGISTIC, which accounts for the complex survey design and weights. The same set of covariates was included in all models: Education, homeownership, whether any language spoken besides English, race, and ethnicity. These co-variates were selected based on previous Census research indicating that they predicted participation [16].

\section{Results}

\section{Self-report data}

We first report on analyses conducted with self-reported 2010 CICPE evaluation wave 3 data. Next, we report on follow up analyses using actual observed Census mail return as the dependent variable.
Table 1 below displays descriptive statistics and reliability analysis of the MR index.

Table 2 presents results from a cross-tabulation of the overall MR factor scores for all respondents by high and low levels of knowledge, positive attitudes, negative attitudes, and exposure to the 2010 ICC. Knowledge scores were calculated by summing the number of correct answers to 8 knowledge questions. The positive attitude index is a count of the number of times respondents reported "strongly agree" to a set of statements measuring positive attitudes towards the Census (e.g., The Census Bureau's promise of confidentiality can be trusted). By contrast, the negative attitude index is a count of the number of times respondents reported "strongly agree" to a set of statements measuring negative attitudes toward the Census. Exposure was measured through a question asking the number of times a respondent saw or heard anything about the Census in the past 90 days. High and low categories were calculated based on falling in the upper or lower half of the distribution for the set of knowledge, attitudes, and exposure questions. Higher mean MR scores within a cell indicate the row variable is correlated with higher MR for the ad in that column. We found that, by ad, higher MR was correlated with higher scores on the knowledge, positive attitudes, and exposure scores/indices, and on the low negative attitude index. Thus higher MR was consistently correlated with more positive cognitions about the 2010 ICC by ad.

Based on the cross-tabulations, higher MR is associated with more positive 2010 ICC cognitions. This is consistent with previous MR studies in other domains, which have shown that MR is a mediator $[2,6,18]$. To further test these hypothesized relationships, we estimated multivariable regression models shown in table 3 . With each cognition or behavior as the dependent variable, we estimated a regression with $\mathrm{MR}$ as the independent variable.

These analyses controlled for the same multiple respondent characteristics noted above. We initially calculated a full model including all co-variates. Then, we calculated a reduced model including only those co-variates found statistically significant in the full model. These included education level, home ownership, and nonEnglish speaking status. We found that both the knowledge score and attitude factor were positively and significantly associated with higher MR. There was no relationship observed between MR and Census participation intent, however.

As a follow up, we examined differences in relationships between

\begin{tabular}{|c|c|c|c|}
\hline Measures & $\begin{array}{l}\text { Ad } 1 \\
\text { Mean (s.e.) }\end{array}$ & $\begin{array}{l}\text { Population-specific } \\
\text { ad Mean (s.e.) }\end{array}$ & $\begin{array}{l}\text { Ad } 3 \\
\text { Mean (s.e.) }\end{array}$ \\
\hline $\begin{array}{l}\text { HIGH Knowledge Scores } \\
\text { ( } n=1430 \text { cases) }\end{array}$ & $\begin{array}{l}0.46 \\
(0.07)\end{array}$ & $\begin{array}{l}0.60 \\
(0.07)\end{array}$ & $\begin{array}{l}0.89 \\
(0.14)\end{array}$ \\
\hline $\begin{array}{l}\text { LOW Knowledge Scores } \\
\text { ( } n=1678 \text { cases) }\end{array}$ & $\begin{array}{l}0.36 \\
(0.09)\end{array}$ & $\begin{array}{l}0.29 \\
(0.06)\end{array}$ & $\begin{array}{l}0.62 \\
(0.09)\end{array}$ \\
\hline $\begin{array}{l}\text { HIGH Positive Attitude Index } \\
\text { ( } n=1584 \text { cases) }\end{array}$ & $\begin{array}{l}0.51 \\
(0.07)\end{array}$ & $\begin{array}{l}0.63 \\
(0.10)\end{array}$ & $\begin{array}{l}0.90 \\
(0.14)\end{array}$ \\
\hline $\begin{array}{l}\text { LOW Positive Attitude Index } \\
\text { ( } n=1524 \text { cases) }\end{array}$ & $\begin{array}{l}0.31 \\
(0.08)\end{array}$ & $\begin{array}{l}0.27 \\
(0.05)\end{array}$ & $\begin{array}{l}0.62 \\
(0.08)\end{array}$ \\
\hline $\begin{array}{l}\text { HIGH Negative Attitude Index } \\
\text { ( } n=1179 \text { cases) }\end{array}$ & $\begin{array}{l}0.32 \\
(0.08)\end{array}$ & $\begin{array}{l}0.41 \\
(0.05)\end{array}$ & $\begin{array}{l}0.70 \\
(0.10)\end{array}$ \\
\hline $\begin{array}{l}\text { LOW Negative Attitude Index } \\
\text { ( } n=1929 \text { cases) }\end{array}$ & $\begin{array}{l}0.44 \\
(0.07)\end{array}$ & $\begin{array}{l}0.46 \\
(0.07)\end{array}$ & $\begin{array}{l}0.78 \\
(0.10)\end{array}$ \\
\hline $\begin{array}{l}\text { HIGH W3 Total Campaign } \\
\text { Exposure ( } n=1285 \text { cases) }\end{array}$ & $\begin{array}{l}0.65 \\
(0.07)\end{array}$ & $\begin{array}{l}0.72 \\
(0.08)\end{array}$ & $\begin{array}{l}1.12 \\
(0.14)\end{array}$ \\
\hline $\begin{array}{l}\text { LOW W3 Total Campaign } \\
\text { Exposure ( } n=1823 \text { cases) }\end{array}$ & $\begin{array}{l}0.25 \\
(0.06)\end{array}$ & $\begin{array}{l}0.27 \\
(0.04)\end{array}$ & $\begin{array}{l}0.53 \\
(0.07)\end{array}$ \\
\hline
\end{tabular}

Table 2: Message Receptivity to Census Ads by Census Knowledge, Attitudes, Beliefs, and Exposure [mean, (S.E.)]. 
Citation: Douglas Evans W, Yan T, Datta AR (2012) Receptivity to 2010 Census Messages Among the General Public and Hard-to-enumerate Populations. J Mass Commun Journalism 2:126. doi:10.4172/2165-7912.1000126

Page 4 of 6

\begin{tabular}{|c|c|c|c|c|c|c|c|c|}
\hline \multirow[t]{4}{*}{ Outcome } & \multicolumn{4}{|c|}{ Knowledge Score } & \multicolumn{4}{|c|}{ Attitude Factor } \\
\hline & \multicolumn{4}{|l|}{$\mathrm{N}=2,401$} & \multicolumn{4}{|l|}{$N=1,888$} \\
\hline & \multicolumn{2}{|c|}{ Main Effects Model } & \multicolumn{2}{|c|}{ With Interactions } & \multicolumn{2}{|c|}{ Main Effects Model } & \multicolumn{2}{|c|}{ With Interactions } \\
\hline & Coefficient & p-value & Coefficient & p-value & Coefficient & $p$-value & Coefficient & p-value \\
\hline R-square & \multicolumn{2}{|l|}{0.24} & \multicolumn{2}{|l|}{0.27} & \multicolumn{2}{|l|}{0.14} & \multicolumn{2}{|l|}{0.20} \\
\hline Message Receptivity Index & $0.16^{\star *}$ & $<0.01$ & $0.42^{\star *}$ & 0.03 & $0.03^{* *}$ & $<0.01$ & 0.08 & 0.38 \\
\hline \multirow[t]{4}{*}{ Outcome } & \multicolumn{4}{|c|}{ (Wave 2) Intent To Return Census } & \multicolumn{4}{|c|}{ Actual Census Return } \\
\hline & \multicolumn{4}{|l|}{$N=924$} & \multicolumn{4}{|l|}{$N=2731$} \\
\hline & \multicolumn{2}{|c|}{ Main Effects Model } & \multicolumn{2}{|c|}{ With Interactions } & \multicolumn{2}{|c|}{ Main Effects Model } & \multicolumn{2}{|c|}{ With Interactions } \\
\hline & Coefficient & Coefficient & Coefficient & Coefficient & Coefficient & p-value & Coefficient & p-value \\
\hline R-square & \multicolumn{2}{|l|}{0.27} & \multicolumn{2}{|l|}{0.27} & \multicolumn{2}{|l|}{0.08} & \multicolumn{2}{|l|}{0.09} \\
\hline Message Receptivity Index & 0.02 & 0.02 & 0.02 & 0.02 & 0.04 & 0.47 & 0.00 & 0.98 \\
\hline
\end{tabular}

Note: Weighted least squares were calculated for knowledge scores and attitude factors; logistic regressions for self-reported form return and Wave 2 intent. Standard errors were corrected for complex survey design. ${ }^{*}$ indicates significance at 0.1 level, ${ }^{* *}$ indicates significance at .05 level

Table 3: Predicting Knowledge, Attitude, Intent to Return Census form, and Actual Census Form Return by Message Receptivity.

MR and 2010 ICC outcomes for each of the major sub-populations targeted in the campaign for which 2010 CICPE had adequate sample size. The sub-populations included Hispanic, non-Hispanic AfricanAmerican, American-Indian, Asian, Native Hawaiian, and nonHispanic Whites. We developed similar multivariable regression models for each sub-population and used the same co-variates as in previous analysis. We estimated a reduced model as before and report those results in the appendix. The reduced model excluded non-English speaking status for sub-group analyses of Hispanics who speak Spanish due to co-linearity.

Overall, we found that the relationships between $M R$ and knowledge scores and attitudes index were generally similar across sub-populations-significant associations with some variation in magnitude (See Appendix, Tables 4 and 5). However, we observed no significant relationship between MR and the attitudes index for Asians (Table 5). There was a significant positive relation between MR and intent for non-Hispanic African-Americans and Native Hawaiians, but a significant negative relation between MR and intent for Asians and Non-English speaking Asians (Table 6).

Additionally, we developed models to test whether self-reported exposure to at least one 2010 ICC ad affected the relationship between MR and outcomes. The previous models calculated MR for all respondents, including those who had not reported exposure to any ads. We now restricted the sample to those respondents who had reported exposure to at least 12010 ICC ad and modeled the relationship between MR and outcomes in this sub-sample with the same co-variates as before.

Results of these sub-sample analyses varied from the previous models including the full sample. As shown in table 4, there was no significant relationship observed between MR and knowledge scores for non-English speaking Hispanics exposed to at least one ad and the relationship became negative for Asians exposed to at least one ad and Native Hawaiians exposed to at least one ad. Higher MR was no longer associated with more positive attitudes for all subpopulations exposed to at least one ad except Native Americans (Table 5). There was a positive relation between MR and intent for Native Americans exposed to at least one ad and negative relation for Asians exposed to at least one ad (Table 6).

Overall, higher MR is associated with higher Census-related knowledge and more positive attitudes and beliefs. In previous studies, some population subgroups have been observed to have higher MR because messaging is more salient and appealing to them [11]. In the current study, Hispanics, Native Americans, Asians, and Native
Hawaiians had higher MR, which was predictive of higher knowledge and, more positive attitudes. The 2010 ICC advertising focused on benefits of the Census to local communities and highlighted racially and ethnically diverse community members advocating those benefits. Respondents from these subgroups may have perceived 2010 ICC messaging to be relevant to them, leading to higher MR and more positive outcomes than the general population.

\section{Census mail return data}

Next we estimated similar models using actual Census mail return data as the dependent variable. We recoded the actual Census mail return so that 1 represents Census form completed and returned before the end of 2010 CICPE data collection and 0 otherwise. To further test these hypothesized relationships, we regressed the Census mail return variable on MR using the same co-variates noted earlier. We then estimated a reduced model including only those variables found significant in the initial analysis. We found no relationship between MR and actual Census mail return (Table 3).

We also examined differences in relationships between MR and Census mail return for each of the major sub-populations targeted in the campaign for which 2010 CICPE had adequate analysis sample. As shown in the Appendix, we found a positive association between MR and actual Census Return for Native Americans (Table 7). Restricting to subpopulations exposed to at least one ad, we found positive associations for Hispanics, Native Americans and Native Hawaiians (Table 7).

\section{Discussion}

The purpose of this study was to compare associations between message receptivity and knowledge, attitudes, beliefs and intentions to participate in Census, and actual Census participation. Specifically, we found that higher receptivity to Census messages was predictive of more positive cognitions about the Census and greater Census mailback behavior, overall and among specific subgroups. Thus, if future messages are designed to maximize receptivity, the Census may be able to increase participation. This analysis is important in that it points out one strategic way to potentially improve campaign messages by increasing receptivity-and suggests how best to achieve Census cognitive and behavioral objectives in future efforts. Future campaigns should explicitly design and test messages to which specific audiences including the hard-to-enumerate will be most receptive. Message testing research to identify messages that maximize MR should be conducted. 
First, confirming H1, we found that the three measured items loaded onto one MR factor at the respondent level for each ad. We found that a higher MR factor was consistently correlated with more positive cognitions about the 2010 ICC by individual advertisementfor each ad measured in the 2010 CICPE, the higher the respondent's MR, the more positive their attitudes and beliefs about the ad. We also found that higher MR was associated with more positive attitudes and beliefs about the Census overall, as targeted by the campaign. This is consistent with previous research and suggests that receptivity may affect targeted behaviors. The current study extends previous research in health communication noted earlier by showing MR predicts other social behaviors such as civic participation. Finally, we found that MR was associated with higher actual Census mail return rates among hard-to-enumerate populations including Native Americans, Hispanic Americans who primarily speak Spanish, and Native Hawaiians.

Overall, higher MR was associated with higher Census knowledge and more positive attitudes. This is consistent with the $2010 \mathrm{CICPE}$ evaluation conceptual model and previous research on message receptivity $[2,4]$. Some population sub-groups have higher MR and for those groups higher MR is associated with higher knowledge, more positive attitudes, and greater Census mail return. However, when the sample is restricted to respondents who self-reported exposure to at least 12010 ICC ad, the positive impact of higher MR on knowledge, attitudes, intention, and actual behavior becomes statistically significant for some groups and loses significance for other groups.

These results have important practical implications for the 2010 ICC and future Census campaigns. First, they suggest that the both general population advertising and efforts to reach hard-to-enumerate groups (those that Census media campaigns are intended to motivate) need to be receptive to Census messages in order to create positive attitudes and beliefs about participation. Sub-groups such as Hispanic Americans who primarily speak Spanish, Native Americans, and Native Hawaiians are among the groups with disproportionately low Census participation but for whom message receptivity was a significant predictor both of more positive cognitions and greater likelihood of participation. For these groups, receptivity is especially important and future Census messages should maximize it.

Message receptivity was an important predictor of campaign outcomes and a mediator of those outcomes in previous health campaign evaluations [19-21]. More research should be done to identify effective Census messages and how to 'frame' messages in order to maximize receptivity [22]. Factors underlying message receptivity in specific hard-to-enumerate populations and the general population need to be better understood in order to improve future campaign effectiveness.

The study has two limitations. First, we evaluated receptivity to only three TV ads from a large, multi-channel campaign using mass media, social media, community outreach and other modalities. Thus we have only assessed part of the total 2010 ICC, which represented an effort to saturate all US media markets and consumers. Second, we did not have experimental control over the messages delivered, and thus cannot compare different messaging strategies that may have been used in the 2010 ICC to isolate specific framing effects.

\section{Conclusion}

The effects of a message on attitudinal/behavioral outcomes are related to which aspects of an issue or event are framed [23]. Message framing influences how media users make sense of events, give order to life experiences and construct perceptions of what is going on around them [24,25]. When reporters frame an issue, they select certain aspects of a perceived reality and make them salient in the news [26]. Similarly, communication materials on social and health issues select and highlight certain aspects of the issue (e.g., benefits of Census participation) that affect individual decision making [27].

Several studies of message framing in regard to social and health behavior have compared the effects of communication strategies emphasizing either the benefits/gains of engaging in a behavior versus the costs/losses of failing to engage in a particular behavior. Overall, in the health arena, "gain-framed" behavioral messages tend to be more effective for disease prevention and health promotion than are "lossframed" or "control" messages [28].

There has been considerable research on message receptivity in the health communication $[29,30]$. But what about other social behaviors like civic engagement and Census participation? What message frames are most effective in this area? Little is known on this topic, but given results showing that receptivity to Census messages predicts outcomes, the question is which message frames are most effective? Future Census research should address this topic, future evaluations should incorporate relevant measurements, and campaigns should use the most effective frames identified in research. Future research should build on the current study and link back to the more extensive health literature to examine whether civic engagement messages field could rely more heavily on the health findings.

For example, in this study we found differences in reactions to ICC ads (Table 2), and differences between the high knowledge/attitude receptivity vs. low. One hypothesis is that ICC ads may be more effective in changing or improving knowledge/attitudes among individuals who are predisposed to respond to civic participation messages than convert those who are averse. Future studies should examine whether segmenting audiences based on these criteria would improve campaign effects.

\section{References}

1. Evans WD, Davis KC, Umanzor, Patel K, Khan M (2011) Evaluation of Sexual Communication Messages. BMC Reproductive Health 8: 15.

2. Dillard JP, Shen L, Vail RG (2007) Does Perceived Message Effectiveness Cause Persuasion or Vice Versa? 17 Consistent Answers. Hum Commun Res 33: 467-488.

3. Bruner GC (1998) Standardization and justification: Do Aad scales measure up? Journal of Current Issues and Research in Advertising 20: 1-18

4. Davis KC, Nonnemaker JM, Farrelly MC, Niederdeppe J (2010) Exploring Differences in Smokers Perceptions of the Effectiveness of Cessation Media Messages. Tob Control 20: 26-33.

5. Evans WD, Uhrig J, Davis K, McCormack L (2009) Efficacy Methods to Evaluate Health Communication and Marketing Campaigns. J Health Commun Int Pers 14: 244-254.

6. Petty RE, Cacioppo JT (1986) Communication and persuasion: central and peripheral routes to attitude change. Springer-Verlag, New York.

7. Niederdeppe J, Davis KC, Farrelly MC, Yarsevich J (2007) Stylistic features, need for sensation, and confirmed recall of national smoking prevention advertisements. J Commun 57: 272-292.

8. Donohew L, Lorch EP, Palmgreen P (1998) Applications of a theoretic model of information exposure to health interventions. Hum Commun Res 24: 454-468.

9. Lang A (2000) The limited capacity model of mediated message processing. J Commun 50: 46-70.

10. Southwell BG (2005) Between messages and people: A multilevel model of memory for television content. Commun Res 32: 112-140. 
Citation: Douglas Evans W, Yan T, Datta AR (2012) Receptivity to 2010 Census Messages Among the General Public and Hard-to-enumerate Populations. J Mass Commun Journalism 2:126. doi:10.4172/2165-7912.1000126

11. Biener L, McCallum-Keeler G, Nyman AL (2000) Adults' response to Massachusetts anti-tobacco television advertisements: Impact of viewer and advertisement characteristics. Tob Control 9: 401-407.

12. Palmgreen $P$, Lorch EP, Stephenson MT, Hoyle RH, Donohew L (2007) Effects of the Office of National Drug Control Policy's Marijuana Initiative Campaign on high-sensation-seeking adolescents. Am J Public Health 97: 1644-1649.

13. Donohew L, Zimmerman R, Cupp PS, Novak S, Colon S, et al. (2000) Sensation seeking, impulsive decision-making, and risky sex: implications for risk-taking and design of interventions. Pers Individ Dif 28: 1079-1091.

14. Evans WD, Datta R, Yan T (2012) Paid Media and Hard-to-Reach Populations: Lessons from the 2010 Census. In Tourganeau R, Edwards B, Johnson T, Wolter K and Bates N (Eds.), Hard-to-Survey Populations. New York: Russell Sage.

15. Census Bureau (2010) 2010 Census Integrated Communications Program Evaluation, Office of Management and Budget Supporting Statement, Part A. Retrieved on August 24.

16. Census Bureau (2012) 2010 Census: State Population Profile Maps. Evaluation Report. Retrieved on August 23.

17. Comry AL, Lee HB (1992) A first course in factor analysis. (2ndedn), Hillsdale, $\mathrm{NJ}$ : Lawrence Erlbaum.

18. Evans WD, Blitstein J, Davis KC, Ulasevich A (2011) Mediators of Parent-Child Communication About Sexual Activity. Am J Health Behavior 35: 428-437.

19. Slater MD, Kelly KJ, Lawrence FR, Stanley LR, Comello ML (2011) Assessing Media Campaigns Linking Marijuana Non-Use With Autonomy and Aspirations: "Be Under Your Own Influence" and ONDCP's "Above the Influence". Prev Sci 12: $12-22$.

20. Huhman ME, Potter LD, Nolin MJ, Piesse A, Judkins DR et al. (2010) The
Influence of the VERB Campaign on Children's Physical Activity in 2002 to 2006. Am J Public Health 100: 638-645

21. Hornik R, Jacobsohn L, Orwin R, Piesse A, Kalton G (2008) Effects of the National Youth Anti-Drug Media Campaign on Youths. Am J Public Health 98: 2229-2236.

22. Goffman E (1974) Frame Analysis: An Essay on the Organization of Experience. Harper and Row, New York.

23. Tversky A, Kahneman D (1981) The Framing of Decisions and the Psychology of Choice. Science 211: 453-458.

24. Iyengar S (1991) Is Anyone Responsible? How Television Frames Political Issues. The University of Chicago Press, Chicago.

25. Scheufele DA (1999) Framing as a theory of media effects. J Commun 49 103-122.

26. Entman RM (1993) Framing: toward clarification of fractured paradigm. J Commun 43: 51-58.

27. Garcia-Retamero R, Galesic M (2010) How to reduce the effect of framing on messages about health. J Gen Intern Med 25: 1323-1329.

28. Kristel M, Gallagher MA, Updegraff JA (2012) Health Message Framing Effects on Attitudes, Intentions, and Behavior: A Meta-Analytic Review. Ann Behav Med 43: 101-116.

29. Niederdeppe J, Bu Q, Borah P, Kindig DA, Robert SA (2008) Message design strategies to raise public awareness of social determinants of health and population health disparities. Milbank Quarterly 86: 481-513.

30. Terry-McElrath Y, Wakefield M, Ruel E, Balch GI, Emery S, et al. (2005) The effect of antismoking advertisement executional characteristics on youth comprehension, appraisal, recall, and engagement. J Health Commun Int Pers 10: $127-143$ 